Gut, 1988, 29, 860-872

Progress report

\title{
Acalculous disease of the gall bladder
}

Cholecystectomy is a common operation in many countries of the world and gall stones are the overwhelming indication. Autopsy studies and sonographic screening in developed countries indicate that at least a quarter of the elderly female population possess gall stones, although the epidemic may have reached its peak.' The extreme prevalence of cholelithiasis diverts attention from the fact that the gall bladder can be host to a number of other conditions (Table), some of which are lethal.

\section{Congenital anomalies}

These are chiefly of importance to the surgeon seeking to identify the biliary anatomy at cholecystectomy. The gall bladder may be rudimentary, absent, duplicate (Fig. 1) or even triplicate. In complete agenesis of the gall bladder the bile duct has a greater risk of developing both gall stones and carcinoma. ${ }^{2}$ The commonest abnormality in shape is the so-called Phrygian cap, a pseudodiverticulum of the fundus that may be mistaken on cholecystography for a pathological septum. ${ }^{3}$ True congenital diverticula and septa are much less frequently encountered. Giant cystic malformation of the gall bladder has recently been reported and could represent a variant of choledochal cyst. ${ }^{4}$

The gall bladder may retain its intrahepatic (fetal) position into adult life, again posing difficulties in identification at operation. Besides situs inversus, other ectopic situations are an attachment to the left lateral segment of the liver and a transverse position on the right side, when the gall bladder may receive both hepatic ducts and drain directly through the bile duct. ${ }^{2}$

Table Acalculous conditions of the gall bladder

\begin{tabular}{ll}
\hline Congenital & - anomalies of number, shape and site \\
& - anomalies of cystic duct \\
& - mucosal heterotopia \\
& - abnormal mesentery (torsion) \\
& - blunt (rare) \\
Traumatic & - penetrating \\
& - iatrogenic (needle puncture, chemical) \\
Inflammatory & - primary (no predisposing cause) \\
(=acalculous & - secondary to operations, burns, trauma \\
cholecystitis*) & - specific (typhoid, staphylococcal, parasitic) \\
& - other (emphysematous, xanthogranulomatous, sclerosing, vasculitic, Crohn's) \\
Degenerative & - cholesterosis \\
Neoplastic & - (pseudotumours) \\
& - adenoma \\
& - other benign tumours (rare) \\
& - melanoma (primary, secondary) \\
& - metastatic carcinoma
\end{tabular}

*acalculous cholecystitis can be acute or chronic. 


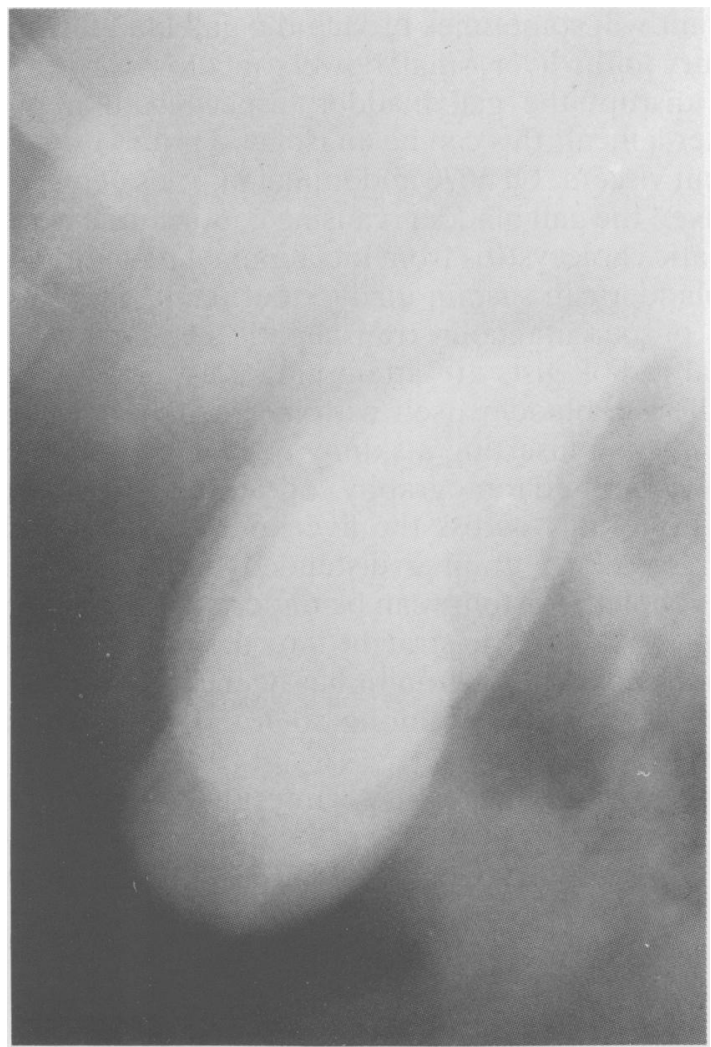

Fig. 1 Oral cholecystogram showing a double gall bladder (by courtesy of DrJ Virjee).

Variations in the 'normal' anatomy of the cystic artery and duct are 'too common to be considered anomalous. Heterotopic tissue in the gall bladder wall can be hepatic, pancreatic, intestinal, or gastric, ${ }^{56}$ exceptionally giving rise to peptic ulcer of the gall bladder.

A 'floating' gall bladder is not uncommon in elderly patients with visceroptosis. The organ is suspended either by a long mesentery attached from the fundus to the neck or by a short mesentery comprising only the cystic duct and artery. ${ }^{89}$ Rarely a floating gall bladder undergoes torsion, either complete or partial and recurrent ${ }^{10}$ the gall bladder can even 'float' into an epigastric hernia." Torsion of the gall bladder typically occurs in elderly women, but children can also be affected. ${ }^{12}$ It has been described in one moiety of a double gall bladder. ${ }^{13}$ The presentation mimics that of acute cholecystitis, and the correct diagnosis is hardly ever suspected before laparotomy. Classically, pain is of sudden onset and there is a tender mass in the right upper quadrant. ${ }^{810}$

\section{Traumatic conditions}

Protected by the overlying liver and costal margin, the gall bladder is seldom involved in abdominal trauma. Penetrating wounds in the right 
upper quadrant will sometimes broach the gall bladder, usually in association with injury to the liver, small bowel, or colon. Severe blunt trauma can occasionally disrupt the gall bladder, especially if it is distended - for example, after a meal; this can be an isolated injury or accompany damage to the adjacent viscera. Of 5670 abdominal injuries of one or other type, 109 $(1.9 \%)$ involved the gall bladder, causing contusion, laceration, avulsion or rarely traumatic cholecystitis from intraluminal haemorrhage..$^{14}$

The gall bladder can sustain inadvertent damage from needles used for liver biopsy or percutaneous transhepatic cholangiography. Nowadays, interventional radiologists are attempting diagnostic and therapeutic procedures on the gall bladder itself with increasing enthusiasm. ${ }^{15}$ Diagnostic manoeuvres involve inserting a skinny needle into the gall bladder under ultrasound or computed tomography control, either by direct percutaneous puncture or preferably across the liver and the nonserosal surface of its gall bladder fossa. To drain a distended and/or infected gall bladder, percutaneous cholecystostomy can be undertaken by dilating up the needle track or by passing a trocar straight into the lumen. In skilled hands the reported incidence of bile peritonitis has been remarkably low; indeed there were no such complications among some 50 diagnostic and therapeutic procedures in two recent series. ${ }^{1516}$

Another type of iatrogenic injury can result from the repeated infusion of chemotherapeutic agents through a catheter placed in the hepatic artery for the treatment of colorectal liver metastases. ${ }^{17}$ Initially there is an acute cholecystitis with mucosal necrosis, and these changes progress to chronic fibrosis. The rapidly increasing use of implantable pumps for the delivery of drugs such as fluoro-deoxyuridine will magnify this problem unless prophylactic cholecystectomy is adopted as a routine. ${ }^{18}$

\section{Acute acalculous cholecystitis}

Between six and $17 \%$ of gall bladders removed for acute cholecystitis contain no gall stones $;{ }^{19-22}$ the proportion may be increasing. ${ }^{23}$ In Glenn's retrospective review of 139 such patients, about half had a predisposing cause and half did not. ${ }^{19}$ These predisposing causes included surgical operations (remote from the biliary tract), multiple injuries, burns, recent childbirth and severe sepsis. Thus acute acalculous cholecystitis is often encountered in the intensive care unit. An attack of calculous cholecystitis after an operation could just be coincidence, yet nearly half the postoperative cases are acalculous; among post-traumatic cases no less than $92 \%$ of patients have no gall stones. ${ }^{24}$

Several aetiological mechanisms have been postulated for acute acalculous cholecystitis, leaving aside rare circumstances like torsion, trauma, and intra-arterial drug therapy. Multiple blood transfusions were implicated in young American soldiers wounded in Vietnam, because of the increased pigment load. ${ }^{25}$ Likewise dehydration might increase bile viscosity, and both parenteral nutrition and assisted ventilation (with positive end expiratory pressure) can cause bile stasis. ${ }^{2026}$ Under these circumstances normal constituents of bile such as lysolecithin and bile acids could damage the mucosa and initiate cholecystitis. ${ }^{27}$ Repeated doses of opiates in postoperative or traumatised patients would lead to prolonged sphincter spasm and perhaps increase luminal pressure in the gall bladder 
above systolic blood pressure. ${ }^{28}{ }^{29}$ Ischaemia could also result from increased sympathetic tone or atheroma, many of these patients being elderly. ${ }^{30}$ Previous vagotomy, primary papillitis and the presence of a long, tortuous cystic duct have also been incriminated in the aetiology of acalculous cholecystitis. ${ }^{31}$ In children, where $30 \%$ of gall bladder disease is acalculous, cystic duct obstruction could result from congenital narrowing or local inflammation; ${ }^{32}$ the duct may be compressed by enlarged lymph nodes.$^{33}$ One fatal case in a premature infant was attributed to parenteral nutrition. ${ }^{34}$ Whatever the underlying cause circulating organisms may compound the infection $;{ }^{28}$ the same bacterium can often be grown from bile and blood alike..$^{25}$

There are no specific clinical or histological differences between (acute) calculous and acalculous cholecystitis, though the proportion of men is higher in the absence of gall stones and the overall mortality is twice as high for example, $9.6 v 4.3 \% .^{23}$ In postoperative and post-traumatic patients gangrene and perforation of the gall bladder are common sequelae (in about $60 \%$ of cases) and explain the high mortality rates observed $(32-47 \%) .^{283536}$ The classical signs of fever, tenderness and a mass are often not detected at an early stage in these critically ill patients. Gangrene is either focal or diffuse, when it can cause bizarre complications such as bleeding into the colon $^{37}$ or pulmonary bile embolism. ${ }^{38}$

The diagnosis of acute acalculous cholecystitis requires a high index of clinical suspicion. There is usually a leucocytosis, and serum concentrations of bilirubin, liver enzymes and amylase may be increased ${ }^{39}$ indeed patients can be mildly jaundiced. When peritonitis supervenes, perforated stress ulcer is an alternative possibility. ${ }^{40}$ Ultrasonography is the simplest investigation. It can be done at the bedside using a portable real time scanner. Positive findings include mural thickening, distension of the gall bladder, sludge within the lumen and the halo sign of subserosal oedema. ${ }^{41}$ Cholescintigraphy using technetium labelled iminodiacetic acid may be a more sensitive technique than ultrasound, however..$^{22}{ }^{30}$ Non-visualisation of the gall bladder despite good hepatic uptake and the entry of isotope into the small intestine is taken as positive evidence of cholecystitis. Moreover, increased pericholecystic activity (the 'rim' sign ${ }^{42}$ ) can indicate the complication of gangrene, and exceptionally free peritoneal spill will diagnose perforation of the gall bladder. ${ }^{22}$ Indium labelled leucocytes offer an alternative method for diagnosing a 'hot' gall bladder in this disease. ${ }^{43}$

The best treatment of acute acalculous cholecystitis (and arguably of the calculous variety) is prompt laparotomy and cholecystectomy. ${ }^{26283536}$ Cholecystostomy is a poorer option because of the risk of extensive gangrene; moreover, the tube may subsequently become blocked or extruded. ${ }^{44}$ Nevertheless, cholecystostomy can be a life saving procedure when carried out under local anaesthetic in a desperately ill patient. ${ }^{45} 46$ It may be particularly appropriate in children, in whom gangrenous changes are uncommon. ${ }^{33}$ As for prophylaxis, it has been suggested that the periodic administration of oral fat or intravenous cholecystokinin might overcome biliary stasis and prevent the development of acute acalculous cholecystitis among high risk patients in a surgical intensive care unit. ${ }^{2026}$

\section{Chronic acalculous cholecystitis}

Although some degree of chronic inflammation is an inevitable accompani- 
ment of cholelithiasis, these pathological changes can occur in the absence of gall stones. ${ }^{47}$ In two recent series, chronic cholecystitis was acalculous in $12-13 \%$ of cases. ${ }^{21}{ }^{18}$ Postinflammatory stenosis or primary tortuosity of the cystic duct might inhibit normal emptying of the gall bladder. ${ }^{31450}$ Gall bladder dysfunction is suggested by low concentrations of biliary lipids in duodenal juice. ${ }^{51}$ Such patients may have persistent pain in the right upper quadrant. They pose diagnostic difficulties because repeat ultrasound scans and oral cholecystograms are often normal. The two tests combined with scintigraphy, however, can give an overall sensitivity of $85 \% \cdot{ }^{48}$ Reproduction of pain within 5-10 minutes of an iv injection of cholecystokinin (CCK) can also select a group of patients who will benefit from cholecystectomy. ${ }^{5052}$ If the CCK provocation test is done during oral cholecystography, poor concentration and incomplete emptying of the gall bladder are observed..$^{49} 53$

\section{Rare types of cholecystitis}

Typhoid fever can cause either acute or chronic cholecystitis. ${ }^{19}$ Such patients may harbour salmonellae in the bile for the rest of their life and could be at increased risk of gall bladder carcinoma. ${ }^{54}$ Acute dilatation (hydrops) of the gall bladder may develop in children with typhoid, leptospirosis, or other systemic infections and can settle with conservative treatment. ${ }^{55}$ Staphylococci can rarely cause acute cholecystitis, presumably reaching the gall bladder via the bloodstream. ${ }^{56}$

Acute emphysematous cholecystitis results from gas forming organisms, notably clostridia and coliforms. Typically it occurs in male diabetics, who develop sudden onset of pain and fever ${ }^{57} 58$ there may be a mass, and toxicity is often severe. The gas filled gall bladder gives a classical appearance on plain abdominal radiograph (Fig. 2). The primary lesion in emphysematous cholecystitis may be occlusion of the cystic duct ${ }^{57}$ or cystic artery, ${ }^{58}$ infection being secondary.

Xanthogranulomatous cholecystitis is a rare condition in which the gall bladder is shrunken, nodular and chronically inflamed with foci of necrosis and haemorrhage. ${ }^{59}$ Abundant histiocytes packed with lipids impart a yellow colour to its wall. Gall stones are usually present. The same condition is described in the kidney, again in association with chronic infection and lithiasis. Mass lesions can sometimes form pseudotumours.

The gall bladder is quite often affected in polyarteritis nodosa, ${ }^{60}$ but acute cholecystitis is rare. Acute dilatation has been reported in mucocutaneous lymph node (Kawasaki) syndrome ${ }^{61}$ and Sjögren's disease, ${ }^{62}$ and chronic inflammation in systemic sclerosis. ${ }^{63}$ The typical changes of Crohn's disease have been described in the gall gladder of a man with granulomatous enteritis. ${ }^{64}$ Lastly, the cystic duct and the gall bladder are commonly involved in patients with sclerosing cholangitis. ${ }^{65}$

\section{Cholecystoses}

In cholesterosis (cholesterolosis) of the gall bladder triglycerides and cholesterol esters are deposited within macrophages in the lamina propria and also in the epithelial cells. ${ }^{66}$ These deposits sometimes project from the mucosa as tiny cholesterol polyps. ${ }^{5}$ Diffuse cholesterosis produces the 


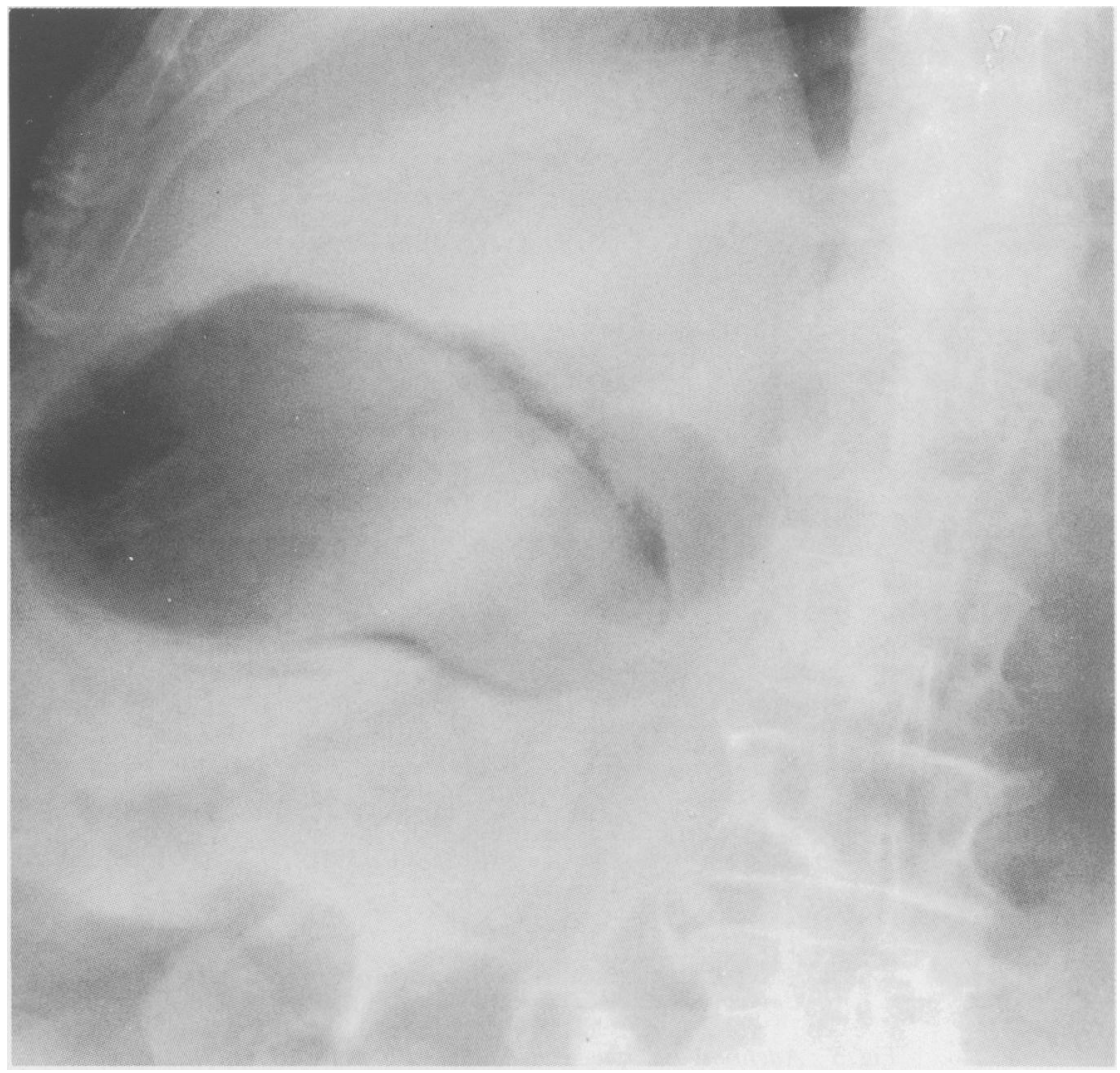

Fig. 2 Plain abdominal radiograph in a patient with acute emphysematous cholecystitis. The gall bladder is clearly outlined by gas in its wall.

'strawberry gall bladder', with yellow flecks of cholesterol highlighted against a red background of mildly inflamed mucosa. The polyps can break off and form a nidus for cholesterol gall stones, which are found in 10-15\% of cases. ${ }^{66}$ The aetiology is obscure but may reflect increased hepatic synthesis of cholesterol and/or its precursor, methyl sterols, and increased absorption from the gall bladder lumen and esterification in the wall; excess cholesterol (or free sterols) is present in the bile but not the blood. ${ }^{67}$ Cholesterosis is not just the sequel of lithogenic bile: cholesterol gall stones frequently develop in its absence and the changes are irreversible with bile acid therapy. ${ }^{6}$

Adenomyosis (adenomyomatosis) of the gall bladder is characterised by hyperplasia of the mucosa and especially the muscularis and by intramural diverticula or crypts (Rokitansky-Aschoff sinuses) ${ }^{68}$ The localised form is sometimes termed adenomyoma, but it is not a true neoplasm; it consists of a sessile mass in the fundus, which bulges into the lumen and is often umbilicated. ${ }^{5}$ The segmental form is marked by a constricting ring or septum in the fundus or body, which separates the gall bladder into two compartments. ${ }^{66}$ The diffuse form causes generalised thickening of the wall with 
structures resembling glands or cysts, hence the alternative names cholecystitis glandularis proliferans and diverticulosis. ${ }^{3}$ Pigment stones are commonly trapped in the diverticula. The aetiology of adenomyosis is unknown, but increased luminal pressure seems a plausible mechanism (as in colonic diverticulosis). ${ }^{66}$ Muscular dysfunction, spasm and stenosis of the cystic duct have been incriminated. ${ }^{3}$

These common types of 'hyperplastic cholecystosis' may coexist with rarer types, such as neuromatosis, lipomatosis, and hyalocalcinosis (porcelain gall bladder).$^{69}$ They may be clinically silent or cause symptoms suggestive of gall stones, which coexist in up to $20 \%$ of cases. ${ }^{70}$ Although adenomyosis or cholesterosis may be present in some $20 \%$ of cholecystectomy specimens ${ }^{66}$ their radiological detection rate is much lower. The mural thickening and diverticula may be visualised on ultrasound or even computed tomography scan, ${ }^{7172}$ but oral cholecystography (with or without CCK) is probably superior (Fig. 3). ${ }^{6870}$ Symptomatic patients generally benefit from cholecystectomy even in the absence of gall stones. ${ }^{47}$ 


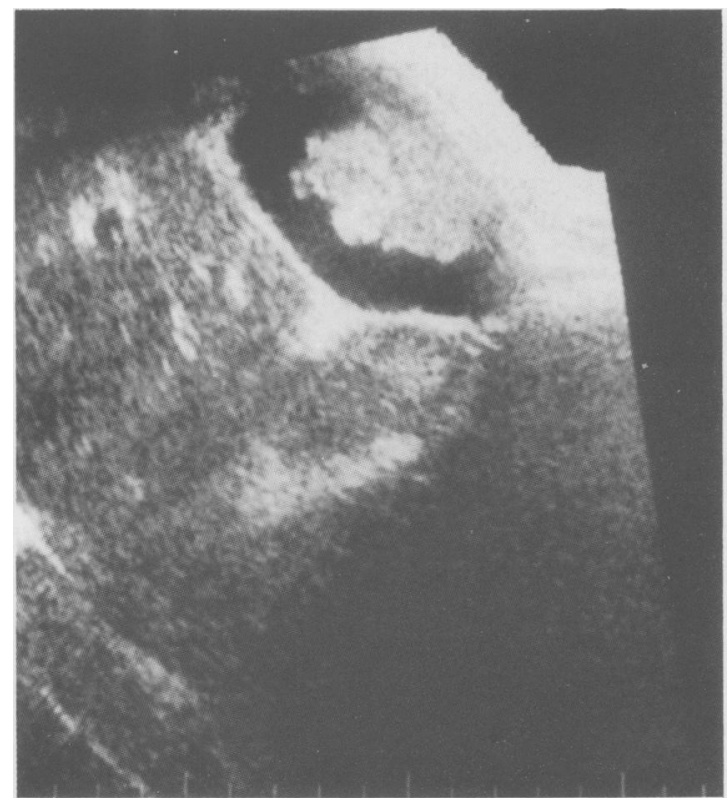

Fig. 4 Ultrasound scan of the gall bladder showing a large papillary carcinoma arising from a pre-existing adenoma.

\section{Neoplasms}

Pseudotumours include inflammatory polyps, cholesterol polyps, heterotopic nests and adenomyoma, the localised form of adenomyosis. ${ }^{5}$ Adenoma is the commonest type of true benign neoplasm. ${ }^{73}{ }^{74}$ It can be either sessile or papillary and is usually solitary. Adenomatous gall bladder polyps have been described in Peutz-Jeghers syndrome. ${ }^{75}$ Some $10 \%$ of adenomas are multiple, and a similar percentage show evidence of carcinoma in situ. ${ }^{76}$ As in the intestinal tract, it is probably the larger adenomas that undergo malignant transformation (Fig. 4). ${ }^{74}$ Intestinal metaplasia (especially goblet cells) can be found in large adenomas and may be a premalignant change, as it is in the stomach; $;^{77}$ certainly some carcinomas of the gall bladder have a predominantly intestinal appearance. ${ }^{78}$

Although adenomas are often incidental findings at operation or autopsy or on radiograph, they are commonly associated with gall stones and chronic cholecystitis. ${ }^{76}$ They can also cause symptoms in their own right - for example, by breaking off and obstructing the cystic duct.$^{76}$ The probability of an adenoma-carcinoma sequence makes cholecystectomy advisable even for asymptomatic polyps..$^{7479}$ Other benign neoplasms of the gall bladder include fibroma, lipoma, myoma, myxoma, carcinoid, and haemangioma, but all are exceedingly rare. ${ }^{80} 81$

Carcinoma of the gall bladder is the fifth commonest cancer of the digestive tract. A retrospective review in 1978 of over 6000 cases emphasised its strong aetiological link with cholelithiasis: three in four patients had gall stones and a similar percentage were women. ${ }^{82}$ More recent reports, ${ }^{82-86}$ including our own from Bristol, ${ }^{87}$ confirm the prevalence of gall stones $(60-92 \%)$ and the female sex and indicate the grim prognosis of gall bladder 
cancer, with five year survival rates of $1-3 \%$. Nearly all series show that cure is impossible once the tumour has breached the gall bladder wall, though there is one discrepant report. ${ }^{88}$ Presumably gall bladders containing stones develop cancer as a result of irritative trauma and chronic inflammation. In experimental animals carcinoma can be induced by inserting a sterile glass rod into the gall bladder, ${ }^{89}$ but also by implanting radium, ${ }^{89}$ methylcholanthrene, ${ }^{(0)}$ cholesterol pellets in association with oral dimethylnitrosamine, ${ }^{91}$ and paraffin pellets containing $\mathrm{N}$-ethyl- $\mathrm{N}^{\prime}$-nitro-Nnitrosoguanidine..$^{92}$

The true incidence of cholelithiasis in gall bladder cancer may be even higher than the reported figures, because resection is not attempted in advanced cases ${ }^{87}$ Nevertheless it never reaches $100 \%$, and in some countries it is much lower - for example, $34 \%$ in Hong Kong, where pyogenic and parasitic disease of the biliary tree is common. ${ }^{93}$ Other potential predisposing causes are occupation carcinogens, ${ }^{94}$ ulcerative colitis, ${ }^{95 \%}$ and the typhoid carrier state..$^{597}$

Japanese workers have recently shown an association between carcinoma of the gall bladder and an anomalous connection of the bile duct with the pancreatic duct; ${ }^{9899}$ the anomaly is also linked with choledochal cyst and cholangiocarcinoma. The aetiological mechanism in each case may be reflux of pancreatic juice into the biliary tree, and high amylase concentrations have been reported in the bile. ${ }^{100}$ It now appears that there may be two variants, ${ }^{100}$ although they both feature a long common channel with the ductal union outside the duodenal muscle and thus beyond the control of the sphincter of Boyden. ${ }^{101}$ When the bile duct joins the main pancreatic duct, it tends to become ectatic above a narrow distal segment and choledochal cyst eventuates. ${ }^{100}$ When the pancreatic duct joins the bile duct, there seems to be an increased risk of gall bladder carcinoma; mucosal metaplasia is a frequent accompaniment.

Some $3 \%$ of gall bladder cancers are squamous. ${ }^{82} \mathrm{~A}$ mixed adènosquamous pattern has also been described in animals ${ }^{91}$ and man. ${ }^{100}$ Other malignant tumours are extremely uncommon, though primary melanoma can occur at this site. ${ }^{102}$ Melanoma can also metastasise to the gall bladder from primary sites elsewhere. ${ }^{103}$ The serosal surface of the gall bladder may become involved in a diffuse carcinomatosis, but intraluminal secondaries have occasionally been reported from a variety of other primaries including pancreas, lung, kidney, ovary, colon, liver, and breast. ${ }^{104} 105$

Department of Surgery,

R C N WILLIAMSON

Royal Postgraduate Medical School,

Hammersmith Hospital, London.

Address for correspondence: Prof R C N Williamson, Department of Surgery, Royal Postgraduate Medical School, Hammersmith Hospital, DuCane Road, London W12 0HS

Received for publication 12 January 1988

\section{References}

1 Heaton KW. Cholelithiasis. Curr Opinion Gastroenterol 1985; 1: 696-702.

2 Knight M. Anomalies of the gall bladder, bile ducts and arteries. In: Lord Smith of Marlow, Sherlock S, eds. Surgery of the gall bladder and bile ducts. London: Butterworths, 1981: 97-116.

3 Williams I, Slavin G, Cox A, Simpson P, de Lacey G. Diverticular disease (adenomyomatosis) of the gallbladder: a radiological-pathological survey. Br J Radiol 1986; 59: 29-34. 
4 Lobe TE, Hayden CK, Merkel M. Giant congenital cystic malformation of the gallbladder. J Pediatr Surg 1986; 21 : 447-8.

5 Christensen $\mathrm{AH}$, Ishak KG. Benign tumors and pseudotumors of the gallbladder. Report of 180 cases. Arch Pathol 1970; 90: 423-32.

6 Curtis LE, Sheahan DG. Heterotopic tissues in the gallbladder. Arch Pathol 1969; 88: 677-83.

7 Larsen EH, Diederich PJB, Sorensen FB. Peptic ulcer in the gallbladder. A case report. Acta Chir Scand 1985; 151: 575-6.

8 Schlinkert RT, Mucha P Jr, Farnell MB. Torsion of the gallbladder. Mayo Clin Proc 1984; 59: 490-2.

9 Butsch JL, Luchette F. Torsion of the gallbladder. Arch Surg 1985; 120: 1323.

10 Ashby BS. Acute and recurrent torsion of the gall-bladder. Br J Surg 1965; 52: 182-4.

11 Goldman G, Rafael AJ, Hanoch K. Acute acalculous cholecystitis due to an incarcerated epigastric hernia. Postgrad Med J 1985; 61: 1017-8.

12 Greenwood RK. Torsion of the gall bladder. Gut 1963; 4: 27-9.

13 Recht W. Torsion of a double gall-bladder. A report of a case and a review of the literature. Br J Surg 1952; 39: 342-4.

14 Penn I. Injuries of the gall-bladder. Br J Surg 1962; 49: 636-41.

15 VanSonnenberg E, Wittich GR, Casola G, et al. Diagnostic and therapeutic percutaneous gallbladder procedures. Radiology 1986; 160: 23-6.

16 Klimberg S, Hawkins I, Vogel SB. Percutaneous cholecystostomy for acute cholecystitis in high-risk patients. Am J Surg 1987; 153: 125-9.

17 Corrasco $\mathrm{CH}$, Freeny PC, Chuang VP, Wallace S. Chemical cholecystitis associated with hepatic artery infusion chemotherapy. Am J Roentgenol 1983; 141: 703-6.

18 Pietrafitta JJ, Anderson BG, O'Brien MJ, Deckers PJ. Cholecystitis secondary to infusion chemotherapy. J Surg Oncol 1986; 31: 287-93.

19 Glenn F. Acute acalculous cholecystitis. Ann Surg 1979; 189: 458-65.

20 Petersen SR, Sheldon GF. Acute acalculous cholecystitis: a complication of hyperalimentation. Am J Surg 1979; 138: 814-7.

21 Pickleman J, Gonzalez RP. The improving results of cholecystectomy. Arch Surg 1986; 121: $930-4$.

22 Swayne LC. Acute acalculous cholecystitis: sensitivity in detection using technetium-99m iminodiacetic acid cholescintigraphy. Radiology 1986; 160: 33-8.

23 Glenn F, Becker CG. Acute acalculous cholecystitis. Ann Surg 1982; 195: 131-6.

24 Jönsson P-E, Andersson A. Postoperative acute acalculous cholecystitis. Arch Surg 1976; 111: $1097-100$.

25 Lindberg EF, Grinnan GLB, Smith L. Acalculous cholecystitis in Viet Nam casualties. Ann Surg 1970; 171: 152-7.

26 Flancbaum L, Majerus TC, Cox EF. Acute posttraumatic acalculous cholecystitis. Am J Surg 1985; 150: 252-6.

27 Sjödahl R, Tagesson C. On the development of primary acute cholecystitis. Scand $J$ Gastroenterol 1983; 18: 577-9.

28 Du Priest RW Jr, Khaneja SC, Cowley RA. Acute cholecystitis complicating trauma. Ann Surg 1979; 189: 84-9.

29 Orlando R III, Gleason E, Drezner AD. Acute acalculous cholecystitis in the critically ill patient. Am J Surg 1983; 145: 472-6.

30 Fox MS, Wilk PJ, Weissmann HS, Freeman LM, Gliedman ML. Acute acalculous cholecystitis. Surg Gynecol Obstet 1984; 159: 13-6.

31 Lygidakis NJ. Surgery for acalculous cholecystitis. An organic and not a functional disease. Am J Gastroent 1981; 76: 27-31.

32 Traynelis VC, Hrabovsky EE. Acalculous cholecystitis in the neonate. Am J Dis Childh 1985; 139: 893-5.

33 Ternberg JL, Keating JP. Acute acalculous cholecystitis. Complication of other illnesses in childhood. Arch Surg 1975; 110: 543-7.

34 Thurston WA, Kelly EN, Silver MM. Acute acalculous cholecystitis in a premature infant treated with parenteral nutrition. Can Med Assoc J 1986; 135: 332-4.

35 Ottinger LW. Acute cholecystitis as a postoperative complication. Ann Surg 1976; 184: $162-5$.

36 Devine RM, Farnell MB, Mucha P Jr. Acute cholecystitis as a complication in surgical patients. Arch Surg 1984; 119: 1389-93.

37 Brady E, Welch JP. Acute hemorrhagic cholecystitis causing hemobilia and colonic necrosis. Dis Colon Rectum 1985; 28: 185-7. 
38 Proia AD, Fetter BF, Woodard BH, Stickel DL, Meyers WC. Fatal pulmonary bile embolism following acute acalculous cholecystitis. Arch Surg 1986; 121: 1206-8.

39 Fabian TC, Hickerson WL, Mangiante EC. Posttraumatic and postoperative acute cholecystitis. Am Surg 1986; 52: 188-92.

40 Shields MA. Acute acalculous cholecystitis: an important complication of trauma. JR Coll Surg Edinb 1973; 18: 83-6.

41 Bėckman I, Dash N, Sefczek RJ, et al. Ultrasonographic findings in acute acalculous cholecystitis. Gastrointest Radiol 1985; 10: 387-9.

42 Bushnell DL, Perlman SB, Wilson MA, Polcyn RE. The rim sign: association with acute cholecystitis. J Nucl Med 1986; 27: 353-6.

43 Datz FL. Utility of indium "'-labeled leukocyte imaging in acute acalculous cholecystitis. Am J Roentgenol 1986; 147: 813-4.

44 Pheils MT, Duraiappah B. Cholecystostomy for acute cholecystitis. Med J Australia 1975; 1: 418-9.

45 Welch JP, Malt RA. Outcome of cholecystostomy. Surg Gynecol Obstet 1972; 135: 717-20.

46 Long TN, Helmbach DM, Carrico CJ. Acalculous cholecystitis in critically ill patients. Am J Surg 1978; 136: 31-6.

47 Keddie NC, Gough AL, Galland RB. Acalculous gallbladder disease: a prospective study. Br J Surg 1976; 63: 797-8.

48 Raptopoulos V, Compton CC, Doherty P, et al. Chronic acalculous gallbladder disease: multiimaging evaluation with clinical-pathologic correlation. Am J Roentgenol 1986; 147: $721-4$.

49 Giffen WO Jr, Bivins BA, Rogers EL, Shearer GR, Liebschutz D, Lieber A. Cholecystokinin cholecystography in the diagnosis of gallbladder disease. Ann Surg 1980; 191: $636-40$.

50 Sykes D. The use of cholecystokinin in diagnosing biliary pain. Ann R Coll Surg Engl 1982; 64: $114-6$.

51 Einarsson K, Angelin B, Kelter U, Nyberg B, Sonnenfeld T. Biliary colic without evidence of gallstones: diagnosis, biliary lipid metabolism and treatment. Acta Chir Scand 1986; suppl 530: 31-4.

52 Lennard TWJ, Farndon JR, Taylor RMR. Acalculous biliary pain: diagnosis and selection for cholecystectomy using the cholecystokinin test for pain reproduction. Br J Surg 1984; 71: 368-70.

53 Reid DRK, Rogers IM, Calder JF. The cholecystokinin test: an assessment. Br J Surg 1975; 62: 317-9.

54 Axelrod L, Munster AM, O’Brien TF. Typhoid cholecystitis and gallbladder carcinoma after interval of 67 years. $J A M A 1971 ; 217: 83$.

55 Cohen EK, Stringer DA, Smith CR, Daneman A. Hydrops of the gallbladder in typhoid fever as demonstrated by sonography. J Clin Ultrasound 1986; 14: 633-5.

56 Thomas WEG, Thornton JR, Thompson MH. Staphylococcal acalculous cholecystitis. $\mathrm{Br}$ J Surg 1981; 68: 136.

57 Rosoff L, Meyers H. Acute emphysematous cholecystitis. An analysis of ten cases. Am J Surg 1966; 111: 410-23.

58 May RE, Strong R. Acute emphysematous cholecystitis. Br J Surg 1971; 58: 453-8.

59 Reyes CV, Jablokow VR, Reid R. Xanthogranulomatous cholecystitis: report of seven cases. Am Surg 1981; 47: 322-5.

60 Livolsi VA, Perzin KH, Porter M. Polyarteritis nodosa of the gallbladder presenting as acute cholecystitis. Gastroenterology 1973; 65: 115-23.

61 Slovis TL, Hight DW, Philippart AI, Dubois RS. Sonography in the diagnosis and management of hydrops of the gallbladder in children with mucocutaneous lymph node syndrome. Pediatrics 1980; 65: 789-94.

62 Tanaka K, Shimada M, Hattori M, Utsunomiya T, Oya N. Sjögren's syndrome with abnormal manifestations of the gallbladder and central nervous system. $J$ Pediatr Gastroenterol Nutr 1985; 4: 148-51.

63 Copeman PWM, Medd WE. Diffuse systemic sclerosis with abnormal liver and gall bladder. Br Med J 1967; iii: 353-4.

64 McClure J, Banerjee SS, Schofield PS. Crohn's disease of the gallbladder. J Clin Pathol 1984; 37: 516-8.

65 Thorpe MEC, Scheuer PJ, Sherlock S. Primary sclerosing cholangitis, the biliary tree and ulcerative colitis. Gut 1967; 8: 435-48.

66 Berk RN, Vegt JH van der, Lichtenstein JE. The hyperplastic cholecystoses: cholesterolosis and adenomyomatosis. Radiology 1983; 146: 593-601. 
67 Tilvis RS, Aro J, Strandberg TE, Lempinen M, Miettinen TA. Lipid composition of bile and gallbladder mucosa in patients with acalculous cholesterolosis. Gastroenterology 1982; 82: $607-15$.

68 Meguid MM, Aun F, Bradford ML. Adenomyomatosis of the gallbladder. Am J Surg 1984; 147: 260-2.

69 Jutras JA, Longtin JM, Levesque MD. Hyperplastic cholecystoses. Am J Roentgenol 1960; 83: $795-827$.

70 Colosimo C Jr, Vecchioli A, Colagrande C. Hyperplastic cholecystosis: study by ceruletide-assisted cholecystography. Gastrointest Radiol 1983; 8: 255-9.

71 Raghavendra BN, Subramanyam BR, Balthazar EJ, Horii SC, Megibow AJ, Hilton S. Sonography of adenomyomatosis of the gallbladder: radiologic - pathologic correlation. Radiology 1983; 146: 747-52.

72 Izumi N, Koyama W, Irie T, Miyakawa H, Ito Y, Kanayama M, Hasumura Y, Takeuchi J. Ultrasonography and computed tomography in adenomyomatosis of the gallbladder. Acta Radiol (Diagn) 1985; 26: 689-92.

73 Ochsner SF, Ochsner A. Benign neoplasms of the gallbladder: diagnosis and surgical implications. Ann Surg 1960; 151: 630-7.

74 Arbab AA, Brasfield R. Benign tumors of the gallbladder. Surgery 1967; 61: 53540.

75 Foster DR, Foster DBE. Gall-bladder polyps in Peutz-Jeghers syndrome. Postgrad Med J 1980; 56: 373-6.

76 Niv Y, Kosakov K, Shcolnik B. Fragile papilloma (papillary adenoma) of the gallbladder. A cause of recurrent biliary colic. Gastroenterology 1986; 91: 999-1001.

77 Kozuka S, Kurashina M, Tsubone M, Hachisuka K, Yasui A. Significance of intestinal metaplasia for the evolution of cancer in the biliary tract. Cancer 1984; 54: 2277-85.

78 Albores-Saavedra J, Nadji M, Henson DE. Intestinal-type adenocarcinoma of the gallbladder. A clinicopathologic and immunocytochemical study of seven cases. Am J Surg Pathol 1986; 10: 19-25.

79 Tabah EJ, McNeer G. Papilloma of the gall bladder with in situ carcinoma. Surgery 1953; 34: $57-71$.

80 Sewell JH, Miron MA. Benign cavernous hemangioma of the gallbladder. Arch Pathol 1969; 88: 30-1.

81 Majeski JA. Polyps of the gallbladder. J Surg Oncol 1986; 32: 16-8.

82 Piehler JM, Crichlow RW. Primary carcinoma of the gallbladder. Surg Gynecol Obstet 1978; 147: 929-42.

83 Hamrick RE Jr, Liner FJ, Hastings PR, Cohn I Jr. Primary carcinoma of the gallbladder. Ann Surg 1982; 195: 270-3.

84 Wanebo HJ, Castle WN, Fechner RE. Is carcinoma of the gallbladder a curable lesion? Ann Surg 1982; 195: 624-31.

85 Morrow CE, Sutherland DER, Florack G, Eisenberg MM, Grage TB. Primary gallbladder carcinoma: significance of subserosal lesions and results of aggressive surgical treatment and adjuvant chemotherapy. Surgery 1983; 94: 709-14.

86 Kelly TR, Chamberlain TR. Carcinoma of the gallbladder. Am J Surg 1982; 43: 737-41.

87 Anderson JB, Cooper MJ, Williamson RCN. Adenocarcinoma of the extrahepatic biliary tree. Ann R Coll Surg Engl 1985; 67: 139-43.

88 Nevin JE, Moran TJ, Kay S, King R. Carcinoma of the gallbladder. Staging, treatment and prognosis. Cancer 1976; 37: 141-8.

89 Petrov NN, Krotkina NA. Experimental carcinoma of the gallbladder. Ann Surg 1947; 123: 241-8.

90 Fortner JG. Carcinoma of the gallbladder. The experimental induction of primary. Cancer $1955 ; 8$ : $689-700$.

91 Kowalewski K, Todd EF. Carcinoma of the gallbladder induced in hamsters by insertion of cholesterol pellets and feeding dimethylnitrosamine. Proc Soc Exp Biol Med 1971; 136: $482-6$.

92 Ikura K. Studies on experimental gallbladder carcinoma with N-ethyl-N'-nitro-Nnitrosoguanidine in golden hamsters. Jpn J Gastroenterol 1982; 79: 2292-8.

93 Koo J, Wong J, Cheng FCY, Ong GB. Carcinoma of the gallbladder. Br J Surg 1981; 68: 161-5.

94 Diehl AK. Epidemiology of gallbladder cancer: a synthesis of recent data. J Natl Cancer Inst 1980; 65: 1209-14.

95 Ritchie JK, Allan RN, Macartney J, Thompson H, Hawley PR, Cooke WT. Biliary tract carcinoma associated with ulcerative colitis. $Q J$ Med 1974; 43: 263-79. 
96 O’Connor R, Harding B, Greene D, Coolican J. Primary carcinoma of the gall bladder associated with ulcerative colitis. Postgrad Med J 1986; 62: 871-2.

97 Welton JC, Marr JS, Friedman SM. Association between hepatobiliary cancer and typhoid carrier state. Lancet 1979; i: 791-4.

98 Kimura K, Ohto M, Saisho H, et al. Association of gallbladder carcinoma and anomalous pancreaticobiliary ductal union. Gastroenterology 1985; 89: 1258-65.

99 Nagata E, Sakai K, Kinoshita H, Kobayashi Y. The relation between carcinoma of the gallbladder and an anomalous connection between the choledochus and the pancreatic duct. Ann Surg 1985; 202: 182-90.

100 Yamauchi S, Koga A, Matsumoto S, Tanaka M, Nakayama F. Anomalous junction of pancreaticobiliary duct without congenital choledochal cyst: a possible risk factor for gallbladder cancer. Am J Gastroenterol 1987; 82: 20-4.

101 Nagata E, Sakai K, Kinoshita H, Hirohashi K. Choledochal cyst: complications of anomalous connection between the choledochus and pancreatic duct and carcinoma of the biliary tract. World J Surg 1986; 10: 102-10.

102 Anderson JB, Hughes RG, Williamson RCN. Malignant melanoma of the gallbladder. Postgrad Med J 1983; 59: 390-1.

103 Verbanck JJ, Rutgeerts LJ, Van Aelst FJ, et al. Primary malignant melanoma of the gallbladder, metastatic to the common bile duct. Gastroenterology 1986; 91: 214-8.

104 Andry G, Turnbull AD, Botet J, Kurtz RC. Cholesonographic characteristics of cystic duct metastasis causing acute acalculous cholecystitis: case report. J Surg Oncol 1986; 31: $178-81$.

105 Beaver BL, Denning DA, Minton JP. Metastatic breast carcinoma of the gallbladder. $J$ Surg Oncol 1986; 31: 240-2. 